\title{
Terremotos distantes sentidos no Brasil
}

George Sand França ${ }^{1}$, Eveline A. Sayão ${ }^{1}$, Chris B. Fianco ${ }^{1}$, Bruna Almeida ${ }^{1}$

${ }^{1}$ Observatório Sismológico-IG-UnB

Copyright 2018, SBGf - Sociedade Brasileira de Geofísica

Este texto foi preparado para a apresentação no VIII Simpósio Brasileiro de Geofísica, Salinópolis, 18 a 20 de setembro de 2018. Seu conteúdo foi revisado pelo Comitê Técnico do VIII SimBGf, mas não necessariamente representa a opinião da SBGf ou de seus associados. É proibida a reprodução total ou parcial deste material para propósitos comerciais sem prévia autorização da SBGf.

\section{Resumo}

Since 1922, 77 earthquakes have been felt in Brazilian cities, thousands of kilometers away from the epicenter, especially by oscillations of high-rise buildings. Because of the increase of skyscrapers in big cities, such longdistance effects are becoming more frequent. We present a study on the characteristics of the earthquakes and cities more susceptible to cause high-rise buildings to oscillate. Most earthquakes occur at intermediate or large depths and those with magnitudes larger or equal than $5.0 \mathrm{mb}$, such as in the Jujuy and Santiago del Estero regions of northern Argentina, have caused long distance macroseismic effects. Most affected cities lie in sedimentary basins, such as São Paulo and Manaus, which can amplify the ground motions through basin resonance.

\section{Introdução}

No dia 02 de abril de 2018 a população de Brasília sentiu um tremor de terra por volta de10h40min horário local (13h40min, UTC). Este tremor assustou a população que estavam nos prédios da parte central de Brasília. Estas edificações foram evacuadas e a defesa civil acionada. Para espanto geral da população esse tremor não foi resultado de evento político e também não foi devido a uma atividade natural local. Esse abalo foi um terremoto que aconteceu na Bolívia, a cerca de $1.719 \mathrm{~km}$ de distância, com profundidade de $559 \mathrm{~km}$ e magnitude de 6.8 Mw. Pela primeira vez, na capital do Brasil, esse evento é sentido por grande parte da população, entretanto a ocorrência desses fenômenos tem maior frequência do que imaginamos. França e Assumpção (2008) apresentaram pela primeira vez essas ocorrências, buscando entender o porquê de eventos distantes serem sentidos no Brasil, sendo identificados pelo menos três fatores que contribuem: a geologia local, a orientação dos edifícios e crescimento populacional e imobiliário, tendo 0 incremento dos meios de comunicação, que facilitaram a comunicação dos efeitos sentidos. Esse trabalho tem como objetivo atualizar o catálogo com todos os sismos distantes sentidos no país.

\section{Metodologia}

Em 1984, Berrocal et al., publicaram um Boletim Sísmico Brasileiro no livro "Sismicidade do Brasil", onde foi registrado a ocorrência de 19 eventos sísmicos distantes que foram sentidos no Brasil até àquele ano. Entre os anos de 1984 e 2006, o Boletim Sísmico Brasileiro, coordenado pela Sociedade Brasileira de Geofísica, foi a fonte de informações desses eventos. A partir 2006, foi feito o trabalho de coleta de informações de diversas fontes, como registros em jornais (online), na defesa civil, ou mesmo em redes sociais (internet). Foram coletados dados como: cidade e estado sentidos, magnitudes (mb, Ms e Mw), profundidade, momento tensor, latitude, longitude e comentários. Também foram calculadas as distâncias mínima e máxima de cada evento em relação as cidades que relataram terem sentido os tremores. As informações de jornais (online) são armazenados digitalmente, os dados dos eventos adicionados a uma planilha e os alertas de notícias em um arquivo texto, com link do site como descrito por Damaceno et al. (2012) e Silva et al. $(2016,2017)$.

\section{Resultados}

A Figura 1 mostra o mapa com a localização dos eventos distantes sentidos em cidades brasileiras. São 77 eventos, sendo a maioria com origem nos Andes, com magnitudes maiores que 4.4 e intensidade II-III MM, sentidos nos grandes centros.

O histograma da Figura 2 mostra um crescimento no registro das ocorrências na década de 90 . Este aumento é reflexo do crescimento imobiliário e populacional, que fez com que a população sentisse tremores em regiões antes desabitadas, ou com um maior número de pessoas. Os meios de comunicação também foram um advento facilitador de registro destas ocorrências.

Quanto a magnitude, obedecendo uma ordem de preferência para essa estimativa (Mw,Ms,mb), percebese que é bem dispersa. Uma busca pela correlação desta com a profundidade (Figura 3) mostra que os eventos sísmicos sentidos no Brasil ocorrem tanto em ambientes rasos como profundos, com quantidades similares, sendo que os profundos se concentram entre 500 e $660 \mathrm{~km}$ com magnitudes de 6 a 7. Contudo, nem todos os eventos rasos de grandes magnitudes são sentidos em território nacional. É importante mencionar que a maioria dos sismos com magnitudes superiores a 6 e oriundos de regiões como San Juan, Salta, Jujuy na Argentina, Santiago Del Estero, no Chile e norte da Bolívia terão reflexo no Brasil.

Dos eventos sentidos no Brasil, o maior ocorreu no dia 27 de fevereiro de 2010 próxima a costa de Bio-Bio no Chile, com magnitude de $8.8 \mathrm{Mw}$ e profundidade de $22.9 \mathrm{~km}$, tendo sido sentido nas cidades São Paulo e São José no estado de São Paulo e na cidade de Passo Fundo no Rio Grande do Sul. O evento de menor magnitude foi de 4.4 $\mathrm{mb}$, com profundidade de $610 \mathrm{~km}$, que ocorreu na fronteira Peru-Brasil.

O estado de São Paulo (Figura 4), mais precisamente a capital é a região que mais sente essa atividade sísmica (Figura 5). Isto é reflexo direto da densidade demográfica, da própria urbanização somada à geologia da região, sobre a qual a cidade está localizada, que é 
uma bacia sedimentar com o mesmo nome. Esta característica é comum para as regiões Sul, Sudeste e parte do Centro-Oeste (Figura 4). Por outro lado, mesmo não descrito nas figuras aqui, na região Norte, os eventos que são sentidos, em sua maioria, são de origem profunda e de regiões próximas (Norte do Peru e na Fronteira Brasil-Peru), se comparado com as regiões mencionadas acima.

Cabe ressaltar, que apesar das capitais do nordeste estarem localizadas sobre bacias sedimentares, estas, com exceção de Salvador, que está localizada sobre rochas do embasamento, nenhuma delas relatou reflexos de sismos distantes. Este fato está relacionado à distância dos terremotos e a pequena ocorrência de grandes eventos na meso-atlântica.

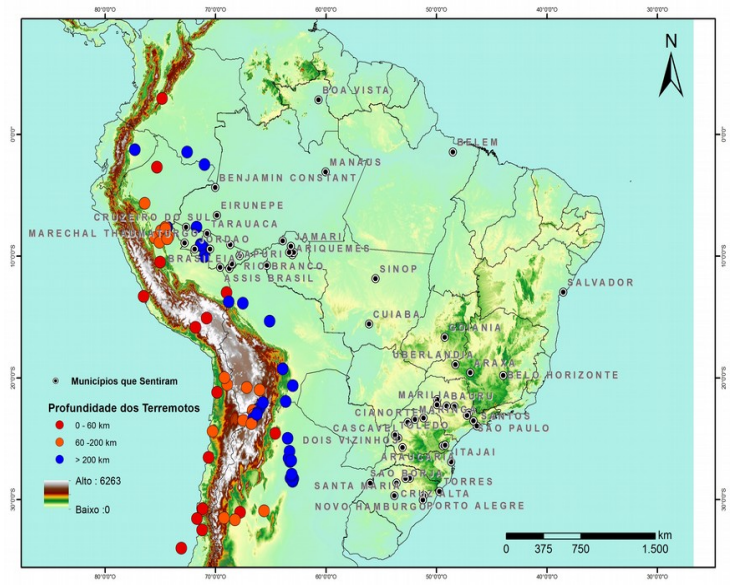

Figura 1: O mapa mostra a distribuição dos sismos distantes com reflexos no Brasil.

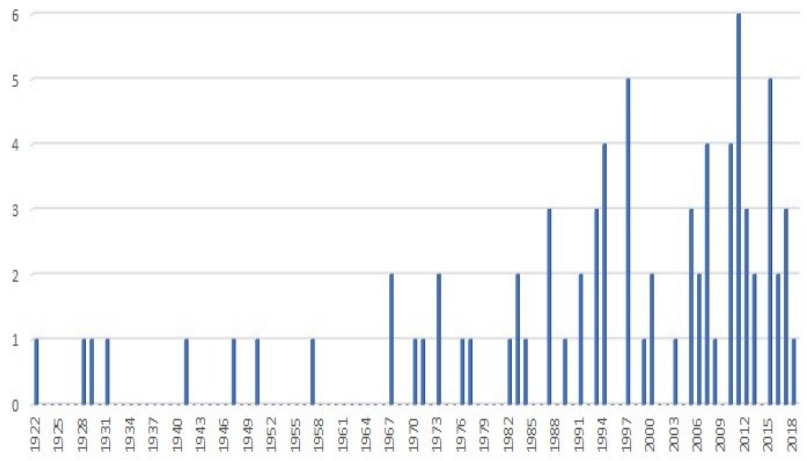

Figura 2: O gráfico mostra o aumento no número de eventos registrados ao longo dos anos, a partir de 1922 até 2018.

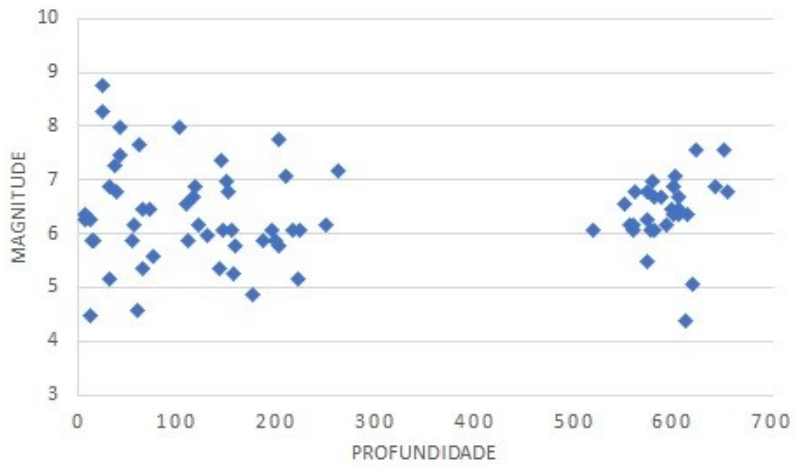

Figura 3: O gráfico mostra a distribuição dos eventos com relação à profundidade de ocorrência e a magnitude, evidenciando a ocorrência bem distribuída em ambiente raso e profundo.

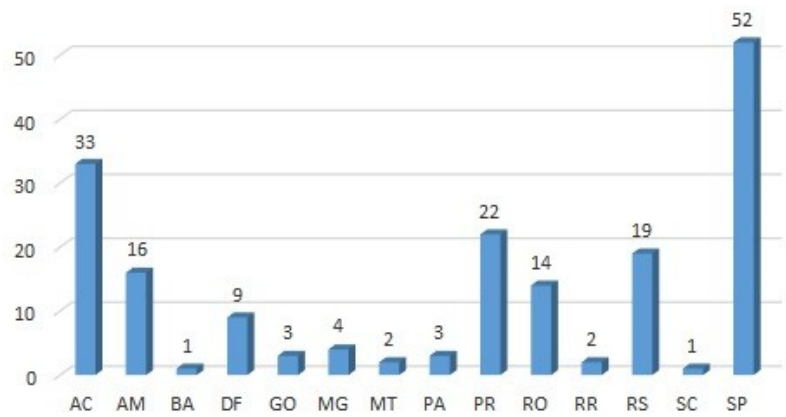

Figura 4: O gráfico mostra a quantidade de eventos com reflexo no Brasil distribuídos por estados, sendo o estado de São Paulo o que apresenta o maior número de registros, seguido pelo Acre.

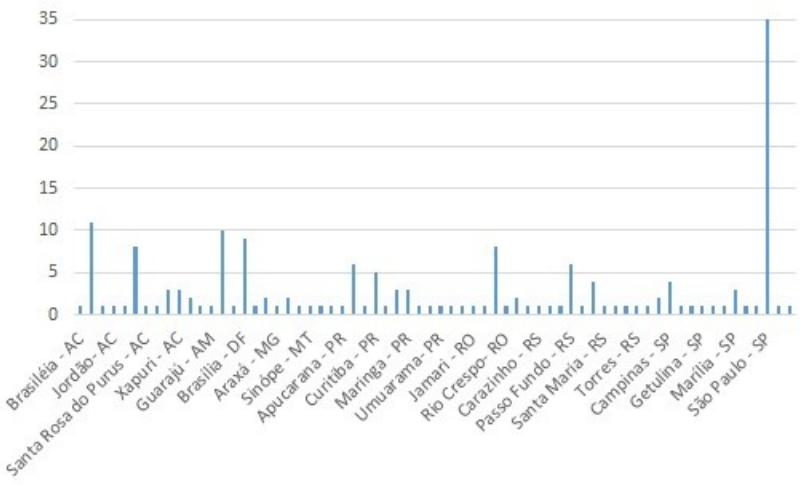

Figura 5: Este gráfico mostra a distribuição dos eventos registrados por cidades, agrupados por estados. Nota-se claramente que o maior número de registros ocorre na cidade de São Paulo.

\section{Discussão e Conclusões}

O trabalho mostra que a ocorrência de eventos sentidos aumentou consideravelmente, e que a origem dos eventos sísmicos é predominantemente andina e profunda.

Nos grandes centros, os fatores como a geologia e grandes construções facilitam o sentimento dos reflexos destes eventos

Com o incremento dos meios de comunicação no país, e a facilidade que a internet, através das redes sociais 
gerou, houve um impulsionamento na coleta de dados e registro destas informações.

Nosso objetivo é continuar este monitoramento e registro de informações, bom como verificar a geologia das regiões que sofrem os maiores efeitos dos eventos distantes.

\section{Agradecimentos}

Ao Tom pelas maravilhosas discussões. GSF agradece ao CNPq, pela bolsa concedida.

\section{Referências}

Berrocal, J., Assumpção, M. S., Antezana, R., Dias Neto, C. M., Ortega, R., Franca, H. e Veloso, J. A. V. 1984. Sismicidade do Brasil. Instituto Astronómico e Geofísico, São Paulo, Brasil, 320 p

França, G. S., Assumpção, M. 2008. Reflexos no Brasil de terremotos distantes. Ciência Hoje, v. 42, p. 20-25.

Damaceno J. G., França G. S. e Maia I. 2012. Macrossismos virtual para apoio a Sismicidade Brasilieira. V Simpósio Brasileiro de Geofísica, Salvador, BA.

Silva, L. F., Costa, M. S., Franca, G. S. L. A. 2016. Macrossismo Virtual: Um Apoio Ao Estudo Da Sismicidade Brasileira. In: VII Simpósio Brasileiro de Geofísica, 2016, Ouro Preto. Geofísica Global. Rio de Janeiro: Sociedade Brasileira de Geofísica.

Silva, L. F., Costa, M. S., Franca, G. S. L. A. 2017. Macrossismo Virtual: Um Apoio Ao Estudo Da Sismicidade Brasileira. In: $48^{\circ}$ Congresso Brasileiro de Geologia. As geotecnologias e o século XXI, 2017, Porto Alegre. Anais de $48^{\circ}$ Congresso Brasileiro de Geologia. São Paulo: Sociedade Brasileira de Geologia, 2017. v. Único. p. 190-190. 